\title{
NUEVOS Y VIEJOS CAMPOS PARA EL ESTUDIO DE LA GUERRA A LO LARGO DEL SIGLO XX: UN MOTOR DE INNOVACIÓN HISTORIOGRÁFICA
}

\author{
New and old fields for the study of war over the Twentieth Century: \\ a driving force of historiographical innovation
}

David Alegre Lorenz

Universitat Autònoma de Barcelona david.alegre.lorenz@gmail.com

Recibido: 02-04-2017 - Aceptado: 25-09-2017

Cómo citar este artículo/Citation:

David ALEGRE LORENZ (2018), "Nuevos y viejos campos para el estudio de la guerra a lo largo del siglo XX: un motor de innovación historiográfica", Hispania Nova, 16, págs. 164-196, DOI: https://doi.org/10.20318/hn.2018.4035
Copyright: (c) HISPANIA NOVA es una revista debidamente registrada, con ISSN I I38-7319 y Depósito Legal M 9472-1998. Los textos publicados en esta revista están -si no se indica lo contrario- bajo una licencia Reconocimiento-Sin obras derivadas 3.0 España de Creative Commons. Puede copiarlos, distribuirlos y comunicarlos públicamente siempre que cite su autor y la revista y la institución que los publica y no haga con ellos obras derivadas. La licencia completa se puede consultar en: http://creativecommons.org/licenses/by-nd/3.0/es/deed.es
Resumen: Este artículo tiene por objeto analizar los principales debates y avances en uno de los campos más punteros y prolíficos de la historiografía a nivel internacional: los estudios de la guerra, también conocidos como nueva historia militar. Para ello propongo un recorrido a través de los cambios que se han producido dentro de éste ámbito durante las dos últimas décadas, así como también un examen crítico de los trabajos y tendencias historiográficas que más han contribuido a ello. En este sentido, planteo una puesta en valor de los estudios de la guerra y destaco su importancia para el conjunto de la historiografía por su capacidad para complejizar nuestro conocimiento y explicaciones del pasado; por el amplio y sugerente abanico de casos de estudio que pone a nuestra disposición; por sus tremendas posibilidades y potencial renovador a nivel metodológico e interpretativo; $y$, no menos importante, por su tremenda actualidad $y$ sus conexiones con el presente.

Palabras clave: estudios de la guerra, nueva historia militar, historia social, estudios de género, estudios culturales, guerra total.

\begin{abstract}
This article is intended to analyze the major discussions and developments in one of the most prolific and a cutting-edge historiographic field on an international level: the war studies, also known as new military history. For this reason I propose a look through the changes which have taken place in this area over the last two decades, as well as a critical review of the works and historiographical paradigms that have contributed in that way. In this sense I defend the value of war studies and its importance for the whole historiography, taking into account specially its capacity to enable a more complex understanding and explanation of the past; the wide and suggestive range of subject matters that place at our disposal; its huge possibilities and renewing potential on a methodological and interpretative level; and last but not least its great influence and connections with the present.
\end{abstract}

Keywords: war studies, new military history, social history, gender studies, cultural studies, total war. 


\section{Guerra, capitalismo y modernidad}

Hace ya muchos años que en los círculos académicos fue cuestionada la tesis que defendía que la violencia o la guerra eran fenómenos pasajeros en el camino hacia la modernidad y la conquista del bienestar. A día de hoy somos bien conscientes de que éstas no sólo no representan regresiones atávicas, sino que han sido y son manifestaciones muy claras de la misma modernidad capitalista y, por supuesto, de las sociedades que las impulsan ${ }^{1}$. Intentar dejar la violencia y la guerra al margen de las ideas de civilización y modernidad supone alimentar el discurso autorreferencial del propio sistema liberal-burgués en que vivimos, analizando la realidad desde sus marcos de referencia y contribuyendo a su legitimación. Pero lo cierto es que estados, paraestados, organizaciones políticas, milicias, guerrillas u organizaciones terroristas, incluso también grandes corporaciones, han recurrido y recurren a la lucha armada y a la violencia para la defensa de variados intereses. Y no sólo eso: también como forma de intentar superar determinados desequilibrios y tensiones estructurales, o para la disputa del poder político, la influencia social, los recursos naturales o la riqueza ${ }^{2}$. Es

NOTA: Este trabajo se ha realizado en el marco del Proyecto de I+D Culturas políticas, movilización y violencia en España, 1930-1950 (HAR2014-53498-P) del Ministerio de Economía y Competitividad. Los debates y visiones ofrecidas aquí se han nutrido en muy buena medida del trabajo y las discusiones mantenidas en el seno de la Revista Universitaria de Historia Militar, empresa en la cual participo como coeditor desde principios de 2015. Quiero aprovechar para agradecer a las/os evaluadoras/es anónimas/os del artículo, por haber contribuido con sus apuntes y recomendaciones a que este artículo pueda cumplir con sus objetivos.

${ }^{1}$ Una reflexión muy interesante sobre la relación entre guerra total y modernidad la encontramos en Bernd HÜPPAUF, "Introduction. Modernity and Violence: Observations Concerning a Contradictory Relationship", en Id. (ed.), War, Violence, and the Modern Condition, XXX, Berlín-Nueva York, De Gruyter, 1997, pp. 1-32. Sobre la verdadera dimensión de la Guerra Civil estadounidense Barrington MOORE, Los orígenes sociales de la dictadura y de la democracia, Barcelona, Crítica, 1976 [1966], pp. 99-134. Para el nexo entre la progresiva imposición del capitalismo y los cambios en el modo de hacer y entender la guerra a lo largo del XIX es importante Philip K. LAWRENCE, "Enlightenment, modernity and war", History of the Human Sciences, 12:1 (1999), pp. 3-25

${ }^{2}$ Una síntesis de referencia para estos temas es la obra de Martin MOWFORTH, The Violence of Development: Resource Depletion, Environmental Crises and Human Rights Abuses in Central America, Londres, Pluto, 2014. Justamente, el autor analiza los múltiples intereses y agentes que operan en Centroamérica imposibilitando la paz y favoreciendo la explotación de sus recursos a través de las nefastas políticas de desarrollo. 
por eso que lo que más ha caracterizado a los conflictos modernos ha sido la conversión del civil en un objetivo bélico más, sobre todo como foco de resistencia potencial o real, por su integración en el tejido productivo y social que sostendría el esfuerzo de guerra $y$, no menos importante, por la utilización de criterios supraindividuales en la identificación del enemigo ${ }^{3}$.

No es casual que la guerra y los ejércitos hayan sido en muchos casos un espacio de cambio político o un instrumento de transformación socio-económica. Nada de esto, por supuesto, implica una lectura positiva del poder armado, sino que más bien se trata de un hecho fácilmente constatable con un simple vistazo al pasado. Es más, ambos han sido utilizados de forma consciente como tal, algo inevitable si tenemos en cuenta lo masivo y el carácter cada vez más omnímodo de lo bélico y lo castrense, capaces de afectar cada vez a más individuos y aspectos de la vida en sociedad $^{4}$. Tanto es así que la guerra total acabó poniendo en cuestión el mismo principio legal de neutralidad, si entendemos ésta por la no injerencia en los conflictos. Efectivamente, los estados neutrales, su tejido industrial y su sector agro-ganadero siguieron (y siguen) lucrándose gracias a la guerra al producir pertrechos para los beligerantes y proveerlos de alimentos y materias primas vitales para el sostenimiento de su esfuerzo bélico. Tanto es así que su apoyo ha sido motivo de enconadas disputas diplomáticas e incidentes militares, hasta el punto que ha podido llegar a decantar la balanza de uno $u$ otro lado en no pocos conflictos. Mientras tanto, los efectos económicos, políticos y culturales de la guerra también han acabado haciéndose sentir en las sociedades de dichos países, sobre todo a causa de los procesos inflacionistas derivados de la exportación masiva, la reducción del mercado

\footnotetext{
${ }^{3}$ A este respecto resulta muy interesante la obra colectiva coordinada por Philippe CHASSAIGNE y Jean-Marc LARGEAUD (eds.), Villes en guerre, París, Armand Colin, 2004, que parte del presupuesto de que en la guerra total la ciudad, por su concentración de población, infraestructuras y tejido productivo, pero también por impacto mediático y moral, se convierte en un objetivo militar preferente. Véase también las obras de Andrew KNAPP, Les français sous les bombes alliées 1940-1945, París, Tallandier, 2014 y Annete BECKER, Oubliés de la Grande Guerre. Humanitaire et culture de guerre: populations occupées, déportés, civils, prisonniers de guerre, París, Pluriel, 2012.

${ }^{4}$ Un buen ejemplo lo encontramos en el conjunto de estudios publicado por Richard WALL y Jay WINTER (eds.), The Upheaval of War: Family, Work and Welfare in Europe, 1914-1918, Cambridge, Cambridge UP, 2005 [1988]. Los diferentes casos analizan para escenarios diversos cómo se vieron afectadas por la Gran Guerra las familias de diferentes extracciones sociales, los niveles de vida y la salud, las formas de consumo, las mujeres, las políticas demográficas o las mentalidades. Para una obra divulgativa bastante influyente que aborda el modo en que afectó a los alemanes corrientes la Gran Guerra en el frente doméstico véase VV. AA., Heimatfront. Zwischen Kriegsbegeisterung und Hungersnot - wie die Deutschen den Ersten Weltkrieg erlebten, Múnich, Bucher, 2014.
} 
interior o la congelación de salarios, pero también de los debates políticos entre los partidarios de uno y otro bando. Sin ir más lejos, eso es lo que ocurrió en España durante la Gran Guerra, especialmente en el año $1917^{5}$.

En muchos casos, las particularidades de la contemporaneidad tienen que ver con fenómenos exclusivamente modernos que no tienen parangón con ningún otro momento anterior de la historia. Pensamos por ejemplo en el ascenso de las masas, la aparición de los estados-nación, la revolución industrial, el desarrollo técnico-científico incesante o la imposición del capitalismo en un mundo cada vez más interconectado. Todos estos factores han contribuido a situar la guerra y la violencia en el centro de los siglos XIX, XX y XXI, por mucho que en los últimos setenta años los conflictos armados hayan sido en cierto modo desterrados de las sociedades occidentales a través de su "exportación" al Tercer Mundo. De hecho, violencia y guerra han tenido mucho que ver en fenómenos esenciales como la forja de los estados modernos o la imposición de unas identidades nacionales. En este sentido, el conflicto paradigmático en la nacionalización de las masas, recuperando el viejo concepto de George Mosse, fue la Primera Guerra Mundial, al menos en lo que respecta a Europa, pero ha habido muchos otros 6 .

Lo que pretendo señalar es que las políticas de la violencia y los conflictos armados no son una caída en la barbarie, más allá del poder metafórico de la idea o de la tétrica realidad que los envuelve, sino una expresión paradigmática de la modernidad $^{7}$. Basta con señalar que los traumáticos acontecimientos que rodearon el final de la Guerra Fría, con guerras civiles e internacionales extremadamente sanguinarias, han sido en buena medida el catalizador de las nuevas miradas debidas a las dos últimas generaciones de historiadores e historiadoras. No por nada, éstas alcanzaron la madurez y la edad adulta con los periódicos y los noticiarios televisivos

\footnotetext{
${ }^{5}$ Maximiliano FUENTES CODERA, España en la Primera Guerra Mundial. Una movilización cultural, Madrid, Akal, 2014 y, también, una reflexión muy sugerente en Carolina GARCÍA SANZ, "Repensar la neutralidad en la Gran Guerra. Una lectura en clave europea", Pedro RUÍZ TORRES (ed.), Repensar el mundo de la Gran Guerra, Zaragoza, IFC, 2015, pp. 183-208.

${ }^{6}$ Para el caso italiano véase Ernest IALONGO, "Solving the Nation's Ills Through War: Italy, the Great War, and National Building", Peace \& Change, 40:2 (2015), pp. 234-243 y Vanda WILCOX, "Encountering Italy: Military Service and National Identity during the First World War", Bulletin of Italian Politics, 3:2 (2011), pp. 283-302. Más allá del marco europeo véase Bina D'COSTA, Nationbuilding, Gender and War Crimes in South Asia, Londres y Nueva York, Routledge, 2012.

${ }^{7}$ El concepto políticas de la violencia es desarrollado en la obra colectiva de Javier RODRIGO (ed.), Políticas de la violencia. Europa, siglo XX, Zaragoza, PUZ, 2014.
} 
dando cuenta de los enfrentamientos armados y los episodios de violencia de masas de la segunda mitad del siglo XX. Pero también cabe destacar a esa generación más joven que ha empezado a investigar en la última década y que vivió las sobremesas de su niñez muy marcadas por lo que ocurría en Bosnia, en Ruanda o, en el caso de España, con el terrorismo de ETA. Todo esto ha llevado a una reevaluación profunda del conjunto del siglo $\mathrm{XX}$, así como de las supuestas bondades del capitalismo y la democracia liberal, triunfantes e "invictas" hasta el estallido de la gran crisis económica del año 2008.

Precisamente, los relatos historiográficos de los últimos años se han descentralizado al poner el foco en el individuo corriente como encarnación y medida del hecho social, algo que ha tenido su correlato en los estudios de la guerra. De este modo hemos podido penetrar y aprehender las dinámicas y equilibrios colectivos, comprender los complejos procesos que operan en la toma y ejecución de decisiones o adentrarnos en los recovecos y laberintos del comportamiento, las emociones y las motivaciones humanas bajo las condiciones extremas impuestas por los conflictos armados. Nada de ello ha supuesto un abandono de la historia militar que tiene por sujetos a las élites político-militares, las diplomacias o los estados, que siempre suelen gozar de buena salud ${ }^{8}$. En cualquier caso, conviene subrayar la necesidad de centrarnos en la llamada gente corriente, encuadrada durante mucho tiempo bajo categorías analíticas como la clase, la sociedad, el género y la nacionalidad, que no por menos necesarias y vigentes dejan de precisar el matiz de la dimensión aportada por lo individual.

Por tanto, existe un interés muy claro, que como casi todo en historia tampoco es nuevo, por ver la cara de la guerra a ras de suelo, es decir, sus efectos sobre los combatientes y los civiles, las motivaciones individuales y colectivas, las praxis, las

\footnotetext{
${ }^{8}$ En línea con lo que decíamos véase toda la tradición de la sociología histórica, que en lo que al estudio de la guerra se refiere bebe directamente de la polemología original. Véase por ejemplo Alex WEISIGER, Logics of War: Explanations for Limited and Unlimited Conflicts, Ithaca, Cornell UP, 2013. Desde mi punto de vista, las perspectivas política, diplomática o estatal siempre deberían ser parte de marcos interpretativos más amplios, capaces de integrar un número amplio de voces y planos de la realidad, como ocurre en el estudio de Christopher CLARK, Sonámbulos. Cómo Europa fue a la guerra en 1914, Barcelona, Galaxia Gutenberg, 2014 o Margareth MACMILLAN, París, 1919. Seis meses que cambiaron el mundo, Barcelona, Tusquets, 2005.
} 
trayectorias personales, etc ${ }^{9} . Y$ esto tiene tanto más sentido si se piensa que el largo siglo XIX y los inicios del XX constituyen la época del llamado ascenso de las masas a la vida pública, con todo lo que ello comportó en el ámbito de la participación política y la implicación en los asuntos comunitarios a todos los niveles. Hoy en día, con el concepto de guerra total bien consolidado en la historiografía, está fuera de toda duda que los enfrentamientos armados, sus dinámicas y sus consecuencias no quedan ni mucho menos restringidos al ámbito del frente, las cancillerías o los centros de mando, sino que afectan al conjunto de las sociedades y culturas en conflicto. ${ }^{10}$

\section{Masculinidades y feminidades: la historia de género en los estudios de la guerra}

No es preciso hacer historia de género para constatar que uno de los factores que más ha contribuido al avance y consolidación de los estudios de la guerra ha sido la presencia e influencia cada vez mayor de la historia de las mujeres y los trabajos debidos a historiadoras ${ }^{11}$. Sin embargo, me ha parecido conveniente subrayarlo y destacarlo en un lugar preferente de este estado de la cuestión, por su especial importancia a la hora de desmontar los discursos hegemónicos y estereotipados en torno a los conflictos bélicos, abriendo así un nuevo horizonte de posibilidades.

\footnotetext{
${ }^{9}$ Dos de los primeros ejemplos vigentes aún a día de hoy son Eric J. LEED, No Man's Land: Combat \& Identity in World War I, Cambridge, Cambridge UP, 1979 y John KEEGAN, El rostro de la batalla, Madrid, Turner, 2013.

${ }^{10}$ Al hablar de "guerra total" se hace referencia a una nueva forma de concebir y hacer la guerra que acompaña a la llegada de la contemporaneidad. Ésta se caracteriza por eliminar las distinciones entre el combatiente y el civil, vistos ambos como enemigos y, por tanto, objetivos militares, al tiempo que plantea una movilización total de los recursos materiales, económicos, sociales, políticos y culturales de las sociedades enfrentadas, con grandes ejércitos de conscriptos y armamento de poder devastador producido en masa por sociedades industriales. Así se explica que uno de sus rasgos más definitorios de este tipo de conflicto pase por exigir la rendición incondicional del enemigo, acompañada por lo general de la conquista, anexión y reordenación territorial, de las políticas de nacionalización e ingeniería socio-demográfica o de la imposición del propio sistema político. Aunque existe debate con respecto al momento concreto de su aparición, lo más sensato es pensar que muchos de sus rasgos se fueron manifestando a lo largo del siglo XIX, cobrando una particular crudeza en los conflictos coloniales del final de la centuria y alcanzando sus rasgos más definitorios y paradigmáticos en el siglo XX. A este respecto véase el impactante estudio de David A. BELL, The First Total War: Napoleon's Europe and the Birth of Warfare as We Know It, Boston, Houghton Mifflin, 2007, al igual que el de John KEEGAN, Secesión: La guerra civil americana, Madrid, Turner, 2011 [2009], que proponen distintos orígenes.

${ }^{11}$ Dagmar HERZOG, "Introduction: War and Sexuality in Europe's Twentieth Century", en Idem (ed.), Brutality and Desire: War and Sexuality in Europe's Twentieth Century, Basingstoke, Macmillan, 2011 [2009], pp. 1-15.
} 
Efectivamente, el estudio del rol y la representación de las mujeres en el marco de las movilizaciones y los enfrentamientos bélicos de la contemporaneidad ha aportado mucha mayor profundidad y amplitud a nuestra comprensión de estos fenómenos, al tiempo que nos ha acercado de forma más fidedigna al funcionamiento de las sociedades en guerra. También ha contribuido al cuestionamiento y la deconstrucción de los roles de género, viendo estos precisamente como constructos maleables al servicio de la estabilidad social y los intereses de unas élites y unos estados plenamente identificados con el heteropatriarcado. $\mathrm{Y}$ aquí me refiero tanto a las masculinidades como a las feminidades, pero también a los roles y relaciones asociadas a ambas. No es casual que estas dos dimensiones del ordenamiento sociocultural se hayan visto radicalmente afectadas por la guerra total, ya fuera porque ésta ha garantizado la continuidad del orden y equilibrios preexistentes, mediante su consolidación, o porque las haya puesto en cuestión ${ }^{12}$.

Todo esto nos ha obligado a repensar el papel de las mujeres en los conflictos, que lejos de ser únicamente víctimas y sujetos pasivos han pasado a verse paulatinamente como lo que son: sujetos activos de las retaguardias y las ocupaciones militares, a veces también de los frentes ${ }^{13}$. Tampoco hay que olvidar el papel de los millones de féminas que se desempeñaron en labores auxiliares dentro de los ejércitos, así como también en los cuerpos sanitarios, encargándose de colaborar con los médicos y cirujanos en sus tratamientos e intervenciones, pero también de asistir a los combatientes durante su convalecencia, de ayudarles a confrontar el trauma, el

\footnotetext{
${ }^{12}$ Sobre el cuestionamiento y los intentos de reconstrucción de la masculinidad en Francia tras la Gran Guerra y la derrota del 40 véase Joan TUMBLETY, Remaking the Male Body: Masculinity and Uses of Physical Culture in Interwar and Vichy France, Oxford, Oxford UP, 2012.

${ }^{13}$ Un trabajo sumamente importante es el de Anna KRYLOVA, Soviet Women in Combat: A History of Violence on the Eastern Front, Cambridge, Cambridge UP, 2010, que analiza el rol de las 120.000 mujeres soviéticas que se presentaron voluntarias para servir en el Ejército Rojo tras la invasión alemana y que sirvieron como soldados en sus filas, llegando algunas de ellas a alcanzar puestos de responsabilidad. Esta notable contribución al esfuerzo de guerra soviético, sin contar las otras 820.000 que se integraron en las fuerzas armadas como auxiliares, fue un tema de debate en el seno del ejército y contribuyó decisivamente a transformar los roles y las relaciones de género en el frente. En esta misma línea, es igualmente sugerente el estudio de Jelena BATINIĆ, Women and Yugoslav Partisans: $A$ History of World War II Resistance, Cambridge, Cambridge UP, 2015. La autora se apoya en un corpus documental vastísimo para demostrar que el hecho de que más de una décima parte de las unidades de combate estuvieran compuestas por mujeres no fue óbice para que se mantuvieran activos los usos y costumbres patriarcales como base de la organización de la guerrilla comunista yugoslava, algo que entraba en línea con la estrategia para ganarse el apoyo de las poblaciones campesinas.
} 
dolor y en última instancia la muerte ${ }^{14}$. $\mathrm{Y}$, finalmente, cabe mencionar a aquellas que en el marco del colonialismo y la guerra total colaboraron de forma activa y militante con las políticas anexionistas y de ocupación promovidas por sus estados dentro de los roles que les fueron destinados, alimentando con ello dinámicas de explotación y violencia ${ }^{15}$.

Si las investigaciones sobre la experiencia de guerra en el frente han coincidido en destacar la importancia del margen de maniobra con que contarían los combatientes en los teatros de operaciones, lo mismo ha ocurrido en el caso de los civiles y, por extensión, de las mujeres que permanecieron en la retaguardia. En el escenario de la guerra total, muchachas, esposas y ancianas no sólo serían el sostén moral de sus padres, hijos, novios y maridos en el frente, sino también de unas economías de guerra que requerían cada vez más mano de obra, cubriendo las vacantes dejadas por los hombres en todo tipo de trabajos, como auxiliares en el ejército u obreras industriales, pasando por servicios de emergencias, etc. Pero además, con unas condiciones materiales cada vez más difíciles y habiendo de garantizar su propia supervivencia y la de su prole, o simplemente agotadas por la larga duración de la guerra, las mujeres se vieron obligadas a tomar decisiones dentro del reducido abanico de posibilidades que les ofrecían unas sociedades dominadas por los hombres.

Muchas de ellas conocieron un grado de libertad nunca antes experimentado, sobre todo una vez desaparecida la autoridad masculina en el seno de la familia; aparecieron nuevas prácticas amorosas, formas de ocio $\mathrm{y}$, también, de sexualidad (algo que por otro lado también es extensible a los hombres, combatientes o civiles); las que aún no se encargaban de gestionar la economía de su hogar se vieron

\footnotetext{
${ }^{14}$ Para un análisis de las enfermeras de la Gran Guerra desde su experiencia véase Christine E. HALLET, Containing Trauma: Nursing Work in the First World War, Manchester, Manchester UP, 2011. En un conflicto de tipo industrial donde el armamento fue concebido para causar el mayor daño físico y grado de destrucción posibles, las enfermeras tuvieron que desarrollar múltiples estrategias para lidiar con sus pacientes en un trabajo extremadamente difícil. A menudo, éstos habían perdido buena parte de los atributos o del aspecto que caracterizan a un hombre como tal, lo cual también hacía difícil sobreponerse al trauma causado por la contemplación de las heridas, el sufrimiento y la impotencia de esos jóvenes heridos, mutilados y moribundos.

${ }^{15}$ Véase una perspectiva amplia en el excelente trabajo de Lora WILDENTHAL, German Women for Empire, 1884-1945, Durham y Londres, Duke UP, 2001 y, más concreto y reciente, Elizabeth HARVEY, Women and the Nazi East: Agents and Witnesses of Germanization, New Haven y Londres, Yale UP, 2003.
} 
empujadas a hacerlo, lo cual pasaba en muchas ocasiones por recurrir al mercado negro o por convertirse ellas mismas en estraperlistas; no menos importante, la ausencia o muerte de los maridos puso a muchas esposas y viudas en contacto con el estado, viéndose obligadas a realizar tramites burocráticos; en muchos otros casos se vieron forzadas a trabajar para el ocupante o, incluso, a buscar protección en él a cambio de favores, que irían desde el desempeño de labores domésticas a las relaciones sexuales; también las hubo que acabaron participando de forma activa en los movimientos de resistencia frente a la ocupación de sus países, ya fuera en labores de apoyo o como enlaces, algo que a su vez posibilitó la entrada de muchas mujeres en la política; la participación en periodos de conflictividad y reivindicaciones laborales tampoco fue extraña a muchas jóvenes; $y$, finalmente, el recurso a la prostitución voluntaria, ya fuera de forma puntual o permanente, como una forma más de ganar independencia o, cuanto menos, de conseguir comida y dinero, algo que en muchos casos propició encuentros interculturales e interraciales que podían llegar a transgredir las jerarquías y barreras culturales preexistentes ${ }^{16}$.

En un extremo completamente contrapuesto encontramos el protagonismo clave de la violencia sexual. Ya sea a través de los matrimonios forzosos, la mutilación genital, la humillación pública, la prostitución forzosa institucionalizada o la violación individual y colectiva, ésta ha sido y sigue siendo una parte fundamental de la violencia de masas, asociada en mayor o menor medida a cualquier conflicto armado. No por nada, desde los años 90 se han escrito ríos de tinta sobre la violación como arma de guerra, algo en lo que tuvo mucho que ver el impacto de lo ocurrido en Bosnia entre 1992 y $1995^{17}$. También sabemos que la violencia sexual depende en gran medida de las coordenadas culturales y el bagaje experiencial de los que la aplican, es decir, de las diferentes concepciones de la sexualidad y de las relaciones de género imperantes en las sociedades de los perpetradores. Es justamente por eso que dicha forma de

\footnotetext{
${ }^{16}$ Es imprescindible la obra de Hanna DIAMOND, Women and the Second World War in France, 19391948: Choices and Constraints, Abingdon-Nueva York, Routledge, 2013 [1999], que pone de manifiesto el papel clave de la mujer francesa en el funcionamiento del mercado negro o el incremento de la prostitución al calor de la ocupación, a pesar de las medidas del régimen de Vichy para tratar de contenerla, así como su continuidad con la llegada de las fuerzas aliadas y la vuelta de los prisioneros de guerra del 40.

${ }^{17}$ Véase, por ejemplo, Allison Ruby REID-CUNNINGHAM, "Rape as a Weapon of Genocide", Genocide Studies and Prevention, 3:3 (2008), disponible online, que aborda las motivaciones, las prácticas y los efectos en los casos de Bosnia, Ruanda y Darfur.
} 
violencia suele servir a múltiples fines, diferentes en función del tiempo y el espacio en que tienen lugar. Por un lado, puede servir como medio para reforzar los vínculos de camaradería y las dinámicas colectivas dentro de los grupos primarios de combatientes, para apuntalar determinadas formas de identidad masculina $o$, simplemente, como una forma más de entretenimiento. Por otro lado, puede ser una forma no necesariamente planificada de destruir las comunidades de procedencia de la víctima, llevando a su marginación, aislamiento y expulsión del grupo; a su inutilidad para la reproducción, por el trauma y heridas sufridas, y para el matrimonio, por la deshonra que comporta para los padres y el posible marido; $y$, en última instancia, al cuestionamiento de la masculinidad de los varones de dicha comunidad, que no habrían sabido defender a sus mujeres ${ }^{18}$.

Precisamente, la cuestión de la masculinidad cobra gran importancia en la contemporaneidad, sobre todo en unos estados y, por extensión, en unos ejércitos modernos con un poder de movilización sin precedentes, tanto en la paz como sobre todo en la guerra. No obstante, ese mismo poder, acompañado de una ambición sin parangón en lo que a sus objetivos se refiere, suele llevar en sí mismo unos límites o un alcance reducido a la hora de poner en marcha las políticas destinadas a encuadrar, controlar y formar a sus ciudadanos-soldados de acuerdo con los patrones modélicos dominantes. Concebidos como escuelas nacionales y contenedores de las esencias patrias, los ejércitos se encontraron muy pronto con una incapacidad manifiesta para gestionar con eficacia los enormes y heterogéneos contingentes humanos movilizados para el servicio militar. La realidad cuestionaba una y otra vez esos ideales de masculinidad, ciudadanía y nación que exigían honrar a la patria; hablar una misma lengua; rezar a un mismo dios; respetar a los superiores y a la

\footnotetext{
${ }^{18}$ En este sentido es imprescindible la obra colectiva ya citada de Dagmar HERZOG, Brutality and Desire..., op. cit., que sigue siendo una de las principales referencias en la materia por su ambición metodológica y conceptual, por la cantidad de casos que engloba y por la calidad de las autoras y autores implicados. Lo mismo puede decirse del conjunto de estudios editado por Nicole Ann DOMBROWSKI (ed.), Women and War in the Twentieth Century: Enlisted with or without Consent, Nueva York, Garland Publishing, 1999. Las diferentes y variadas contribuciones, que al igual que en el anterior caso cubren un arco cronológico que recorre diferentes continentes a lo largo de todo el siglo $\mathrm{XX}$, analizan cuestiones como la representación de la mujer en la guerra, la sexualidad, las experiencias de guerra como civiles, la experiencia de combate en diferentes guerrillas y ejércitos, las violaciones masivas o las particulares formas de conmemorar la guerra por parte de las excombatientes. Por último no podemos olvidar la obra coordinada por Nancy M. WINGFIELD y Maria BUCUR (eds.), Gender \& War in the Twentieth-Century, Bloomington, Indiana UP, 2006, que aborda la experiencia de guerra y los cambios acontecidos en la posguerra a través de diversos casos que toman como centro de su análisis las construcciones y roles de género.
} 
historia nacional; mostrar lealtad y disciplina; sacrificio, abnegación y valentía; ser viril (heterosexual y, por supuesto, arrojado) y cultivar la virtud.

A lo largo de los siglos XIX y $\mathrm{XX}$, millones de reclutas irrumpieron en los cuarteles de todo el orbe con diversos grados de conciencia nacional y diferentes lealtades o sentimientos de pertenencia. Fue en ese momento cuando se constataron con toda crudeza los límites planteados a los estados por la existencia de sociedades diversas ${ }^{19}$. Además, todo ello ocurría en unos ejércitos que a menudo adolecían de los medios necesarios para garantizar una instrucción y formación efectiva de sus reclutas. Esto no sólo fue en detrimento de los intereses del estado, sino que a menudo comportó graves consecuencias a nivel humano, político y cultural sobre las sociedades y, más aún, sobre los colectivos afectados por la conscripción. No obstante, el hecho de que los ejércitos y los estados se encontraran con límites a la hora de implementar sus políticas y alcanzar sus objetivos no significa que éstas, así como también las visiones que las secundaban, no tuvieran efectos reales sobre la realidad del país en cuestión ${ }^{20}$.

\section{El estudio de la vida cotidiana y la experiencia de guerra de combatientes y civiles}

Otra de las cuestiones que más han favorecido la renovación y el avance de los estudios de la guerra ha sido la necesidad de entender la experiencia de guerra, el modus operandi, las condiciones de vida y las transformaciones sufridas por los combatientes al calor de los conflictos modernos, así como su desmovilización y

\footnotetext{
${ }^{19}$ Los casos de los flamencos en la Gran Guerra o los alsacianos y loreneses en la Segunda Guerra Mundial son paradigmáticos por lo que respecta a Europa, pero los ejemplos se multiplicarían si también ampliáramos el foco a contextos no estrictamente bélicos y a otros continentes.

${ }^{20}$ Sobre la importancia de los modelos de masculinidad dominantes véase Jordi LUENGO LÓPEZ, "Homoerótica entre líneas. La «degradación moral» del soldado francés (1879-1914)", Ayer, 87 (2012), pp. 45-66, donde vemos que lo que servía para el ejército era extensible al conjunto de la nación, dado que el primero era considerado como la encarnación de la segunda. El caso de Francia no es para nada diferente al de España, y las crisis de identidad (militares y, no por casualidad, nacionales) que afectaron a este último país tras la pérdida de las colonias de ultramar a finales del XIX o las derrotas en las campañas de Marruecos no son tan diferentes a las que se atravesaron en Francia en el último tercio de dicha centuria tras la derrota en la guerra franco-prusiana, el caso Dreyfus o el Boulanguisme.
} 
reintegración en la vida civil $^{21}$. En ello ha tenido mucho que ver una suerte de fascinación por la capacidad (o incapacidad) de los hombres para soportar y sobrevivir a largos periodos de exposición física, convivencia con la muerte y sometimiento a situaciones materiales de gran miseria. Al fin y al cabo, la guerra total empuja a sociedades enteras dentro de un estrecho cuello de botella que acerca y homogeneiza experiencias partiendo de bagajes previos muy distintos, altera las identidades preexistentes y genera un nuevo paisaje mental caracterizado por otras formas de entender mundo ${ }^{22}$. Cómo se producen estos cambios entre los hombres que protagonizan los hechos en la primera línea del frente es uno de los problemas que han intentado abordar los investigadores e investigadoras en las últimas décadas. ${ }^{23}$

Todo esto ha ido acompañado de un vivo interés por diversas cuestiones: comprender los mecanismos a través de los cuales se produce la entrada e integración de individuos corrientes con orígenes muy diversos en maquinarias de guerra más o menos complejas; cómo se adoptan y cómo operan los marcos de referencia con los que se identifica al enemigo y se hace lícita su eliminación, pero también cuál es el rol de la ideología entre las motivaciones de los combatientes y cómo se manifiesta en su vida diaria; de qué manera afecta al individuo la entrada en contacto con coordenadas humanas y paisajísticas extrañas y, a menudo, percibidas como hostiles, pero también

\footnotetext{
${ }^{21}$ Sin ánimo de sistematicidad, los estudios pioneros serían los ya citados de Eric J. LEED, No Man's Land..., op. cit. y John KEEGAN, El rostro de la batalla..., op. cit., sin olvidar otros muy importantes como Tony ASHWORTH, Trench Warfare 1914-1918: The Live and Let Live System, Basingstoke y Oxford, Pan Books, 1980, Omer BARTOV, The Eastern Front, 1941-45, German Troops and the Barbarisation of Warfare, Nueva York, Macmillan, 1985 y su obra recientemente traducida al castellano El ejército de Hitler. Soldados, nazis y guerra en el Tercer Reich, Madrid, La Esfera de los Libros, 2017. Desde un punto de vista más cultural también fue muy importante el trabajo de George L. MOSSE, Soldados caídos. La transformación de la memoria de las guerras mundiales, Zaragoza, PUZ, 2016 [1990]. Véase, por último, Stephen G. FRITZ: Frontsoldaten: The German Soldier in World War II, Lexington, UP Kentucky, 1995.

${ }^{22}$ Véase Antonio GIBELLI, L'Officina della Guerra. La Grande Guerra e la transformazioni del mondo mentale, Turín, Bollati Boringhieri, 1991, sobre los cambios mentales y las crisis identitarias que tuvieron lugar en la Italia de la Gran Guerra y su posguerra.

${ }^{23}$ Para el caso de España contamos con los estudios de Ángel ALCALDE, Los excombatientes franquistas (1936-1965), Zaragoza, PUZ, 2014; Javier RODRIGO, La guerra fascista. Italia en la Guerra Civil española, 1936-1939, Madrid, Alianza, 2016, Xosé Manoel NÚÑEZ SEIXAS, Camarada invierno. Experiencia y memoria de la División Azul (1941-1945), Barcelona, Crítica, 2016. Todos ellos han contribuido a la transferencia de conceptos y debates clave en los estudios sobre la guerra en el siglo XX. En breve aparecerán también las tesis doctorales de Francisco J. Leira y Miguel Alonso Ibarra, que desde perspectivas diferentes y centradas en casos distintos apuntan en una dirección metodológica y conceptual muy similar.
} 
cómo responde al encuentro con lo desconocido ${ }^{24}$; qué estrategias se emplean para sobrevivir en situaciones de tremenda precariedad material y emocional; cómo funcionan y cuáles son las redes de sociabilidad, la privacidad o los códigos lingüísticos empleados en el frente; cómo se relacionan con sus seres queridos en el frente doméstico, qué visión tienen de éste y qué hacen cuando vuelven a casa de permiso; de qué modo se experimenta y enfrenta la convivencia diaria con la muerte; cómo se relacionan los combatientes con el armamento moderno; qué lugar ocupan el aburrimiento y el ocio en su día a día y cómo se manifestaría este último; qué tipo de relaciones mantendrían con los y las civiles de su entorno; en definitiva, cuáles serían las particularidades de su modus operandi en tiempos de guerra ${ }^{25}$.

${ }^{24}$ Las cuestiones enumeradas hasta aquí quedan englobadas bajo el concepto cultura de guerra, surgido en la historiografía francesa durante los años 90 para el estudio de la Gran Guerra y la comprensión de su extremada virulencia. Este haría referencia al conjunto de discursos oficiales y prácticas ritualísticas que en el marco de una movilización bélica darían sostén al esfuerzo de guerra en un determinado país y legitimarían todas las acciones militares encaminadas a la consecución de la victoria frente a un enemigo deshumanizado y demonizado en la esfera pública. Véase como aportaciones de referencia Stephane AUDOIN-ROUZEAU y Annette BECKER, "Vers une histoire culturelle de la première guerre mondiale", Vingtième Siècle, 41 (1994), pp. 5-9 y, de los mismos autores, 14-18. Retrouver la guerre, París, Gallimard, 2000. Los esfuerzos de González Calleja fueron decisivos a la hora de importar los estudios socio-culturales de la guerra para el estudio de la historia de España. Véase por ejemplo Eduardo GONZÁLEZ CALLEJA (coord.), La cultura de guerra en la España del siglo XX. Historia Social, 61 (2008). Tal es la importancia que se ha conferido a las realidades político-culturales englobadas bajo dicho concepto y a su influencia sobre las sociedades y ejércitos en guerra que autores como Becker y Audoin-Rouzeau ven en la cultura de guerra de cada país como la placenta donde se gesta la guerra total. Sin embargo, en los últimos años se ha criticado este supuesto potencial omnicomprensivo del concepto, por la simplicidad y ausencia de respuestas que entrañaría al haberse convertido en una suerte de entelequia que por sí sola no bastaría para explicar la complejidad de todos los procesos y fenómenos sociales que tienen lugar en el marco de un conflicto armado. Véase otra propuesta interpretativa en el trabajo colectivo de Frédéric ROUSSEAU (ed.), Guerres, paix et sociétés, 1911-1946, París, Atlande, 2004.

${ }^{25}$ Sobre los retos y cambios de mentalidad forzados por el tremendo desarrollo técnico que experimentó la guerra en el siglo XX véase Christian KEHRT, Moderne Krieger. Die Technikerfahrungen deutscher Militärpiloten 1910-1945, Paderborn, Ferdinand Schöningh, 2010. El autor aborda in extenso las experiencias de los aviadores alemanes, así como también los cambios en las formas de representar y entender la guerra por la aparición del arma aérea, entre otras cosas. Véase también el ambicioso estudio de Frédéric ROUSSEAU, La guerre censurée. Une histoire des combattants européens de 1418, París Seuil, 1999, que aborda múltiples aspectos de la experiencia de guerra de los combatientes en la Gran Guerra desde la perspectiva de las emociones, las percepciones y las identidades. En este sentido resulta ineludible la historia socio-cultural de la experiencia de guerra británica y alemana durante la Gran Guerra contenida en la obra de Alexander WATSON, Enduring the Great War: Combat, Morale and Collapse in the German and British Armies, 1914-1918, Cambridge, Cambridge UP, 2008, por su exhaustividad, por la gran cantidad de variables que integra en su análisis y por su carácter comparado. La importancia de los lazos afectivos e ideológicos forjados en los grupos primarios y la camaradería como vector esencial de la experiencia de guerra de los combatientes alemanes en la Segunda Guerra Mundial en Thomas KÜHNE, Kameradschaft. Die Soldaten des nationalsozialistischen Krieges und das 20. Jahrhundert, Gotinga, Vandenhoeck \& Ruprecht, 2006. 
Por lo general, la guerra total va acompañada de ocupaciones más o menos prolongadas que conllevan el control de los territorios o los países conquistados por uno de los beligerantes. Éstas pueden desembocar en todo un abanico de casuísticas diferentes, que van desde el establecimiento de administraciones civiles o militares hasta la presencia permanente de un ejército ocupante, pasando por la creación de paraestados o estados títeres, el impulso de gobiernos afines, la división territorial en base a unos criterios concretos o la simple y pura anexión. Sea cual sea el tipo de ordenación político-territorial o los proyectos implementados casi siempre constituyen una imposición externa y favorable a los intereses del conquistador. No por nada, la injerencia de un poder ocupante en los asuntos privativos de territorios que no estaban previamente bajo su soberanía supone una ruptura de todos los equilibrios políticosociales y económicos preexistentes, así como el posible derrumbamiento de poderes y contrapoderes en el marco de excepción abierto por la guerra. Es decir, la pérdida de soberanía suele venir acompañada de un conjunto de políticas de ocupación guiadas por intereses exteriores: la puesta en marcha de organizaciones militares o paramilitares auxiliares, la explotación económica y laboral, las injerencias en asuntos judiciales, la promoción de determinadas fuerzas políticas y la persecución de otras, las imposiciones culturales y lingüísticas $y$, en determinados casos, la puesta en marcha de políticas de la violencia de diversa naturaleza (saqueos sistemáticos o puntuales, recluta forzosa para el ejército o el trabajo, deportaciones, persecuciones raciales, políticas y religiosas, eliminaciones, etc.).

En este sentido, la guerra y la ocupación abren un nuevo marco propiciatorio donde determinados individuos, sectores sociales, grupos políticos o empresarios encuentran una oportunidad para impulsar sus proyectos personales y colectivos uniendo su destino al de las fuerzas ocupantes. Esto va desde la implementación (o la esperanza) de un nuevo sistema político hasta el incremento de beneficios económicos y la expansión de negocios, pasando por el impulso de carreras artísticas y profesionales, la consecución de ascendiente social y cultural o la resolución de "problemas" concretos. Los ejemplos a lo largo de la contemporaneidad son 
innumerables, empezando por las guerras napoleónicas, y las consecuencias de dichas decisiones a menudo han sido irreversibles y fatales ${ }^{26}$.

Las comunidades, atravesadas ya previamente por las fracturas propias de cualquier sociedad moderna, han experimentado durante los periodos de ocupación la agudización de algunas de sus divisiones preexistentes y la aparición de otras nuevas. Se trata de diferencias que se manifiestan tanto a nivel local y regional como también nacional, ya sean éstas de clase, políticas, nacionales, culturales o religiosas, algo que puede desembocar en episodios de violencia consentida por el ocupante como parte de las políticas de ocupación (divide et impera). No obstante, en este complejo escenario suelen aparecer fenómenos de resistencia armada de todo signo que pueden llegar a enfrentarse entre sí, pero que sobre todo se oponen al ocupante e identifican, estigmatizan y persiguen al que colabora con él como traidor, lo que a su vez sirve para forzar cierres de filas y disuadir a los propios conciudadanos de sumarse a cualquier iniciativa que apoye o favorezca de forma abierta al conquistador ${ }^{27}$.

De este modo nos encontramos con que, al romper los equilibrios preexistentes, los enfrentamientos armados convencionales entre dos o más estados y muy especialmente las ocupaciones actúan muchas veces como acicate para el estallido de guerras civiles de diversa naturaleza e intensidad. ${ }^{28} \mathrm{Y}$ no sólo eso, también contribuyen al crecimiento de opciones políticas radicales antes minoritarias pero ahora capaces de encontrar eco por la exclusividad de que disfrutan bajo la ocupación o por su capacidad para organizarse y dar respuesta a los problemas del momento desde la

\footnotetext{
${ }^{26}$ Algunos estudios de referencia, entre muchos otros posibles, y desde perspectivas diferentes son Götz ALY, Hitlers Volksstaat. Raub, Rassenkrieg und nationaler Sozialismus, Frankfurt del Main, Fischer, 2005; Richard VINEN, The Unfree French: Life under the Occupation, New Haven, Yale UP, 2006; o, también, Dieter POHL, Die Herrschaft der Wehrmacht. Deutsche Militärbesetzung und einheimische Bevölkerung in der Sowjetunion 1941-1944, Frankfurt am Main, Fischer, 2011. En España seguimos careciendo de estudios solventes sobre las políticas de ocupación en la guerra civil, aunque todo hace pensar que serán solventados de la mano de las investigaciones de Miguel Alonso.

${ }^{27}$ Muy recomendable la visión de Martin CONWAY, Collaboration in Belgium: Léon Degrelle and the Rexist Movement, New Haven \& Londres, Yale UP, 1993. Se trata de un estudio que todavía no ha sido superado y que muestra precisamente cómo el colaboracionismo se convirtió en objeto preferente de la violencia de la resistencia y el modo en que los ocupantes y sus aliados enfrentaron esta situación.

${ }^{28}$ Una vez más, el trabajo de González Calleja ha sido fundamental en el acercamiento de los debates en torno al concepto de guerra civil a la historiografía española. Véase Jordi CANAL y Eduardo GONZÁLEZ CALLEJA (eds.), Guerras civiles. Una clave para entender la Europa de los siglos XIX y XX, Madrid, Casa de Velázquez, 2012. También Xosé Manoel NúÑEZ SEIXAS, ¡Fuera el invasor! Nacionalismos y movilización bélica durante la guerra civil española (1936-1939), Madrid, Marcial Pons, 2006.
} 
clandestinidad, pudiendo llegar a conquistar el $\operatorname{poder}^{29}$. Al fin y al cabo, se trata de realidades que serán determinantes en las refundaciones del orden sociopolítico o los periodos de transición durante las posguerras, pero que ponen de manifiesto problemáticas y conflictos, así como también anhelos, esperanzas y diagnósticos, que en muchos casos ya existían con anterioridad al estallido de las hostilidades. Es por eso que los estudios de la guerra han prestado gran atención a las políticas de ocupación, los colaboracionismos y las resistencias armadas, siempre en conexión con el curso de las dinámicas de la guerra en los teatros mayores, que son las que en última instancia condicionan y dan una u otra forma a dichos fenómenos ${ }^{30}$.

En definitiva, los estudios de la vida cotidiana durante los conflictos armados se enmarcan en toda una tradición integrada dentro de la mejor historia social. Esta línea de trabajo que viene siendo cultivada desde hace décadas ha conocido un nuevo impulso con la llegada de lo que algunos han llamado giro emocional. De hecho, lo que busca este enfoque es conocer y explicar cómo afectó la guerra total a la gente corriente, ya fuera entre aquellos enviados a los campos de batalla o entre los que permanecieron en la retaguardia. Precisamente, Stephen G. Fritz se preguntaba si acaso no era una contradicción hablar de vida cotidiana durante la guerra, siquiera por el quebrantamiento que ésta comportaría para el día a día de las comunidades humanas. No obstante, él mismo señalaba que los conflictos dan lugar a sus propios equilibrios, dinámicas y lógicas, una suerte de nueva atmósfera a la que se adaptarían los individuos en su esfuerzo por sobrevivir, un mundo con sus propios usos y costumbres «que se convertiría en normal y "real"» para ellos. En este sentido, la guerra daría lugar a su propia normalidad, con sus particularidades o rasgos distintivos, obligando al individuo a "aprender" a cargar con la incertidumbre de la muerte o la pérdida y a asimilar el sufrimiento, el hambre o la destrucción ${ }^{31}$.

Aún con todo, como destaco en este artículo, las sociedades y los individuos que cohabitan en ellas durante las guerras no son únicamente sujetos sometidos al

\footnotetext{
${ }^{29}$ En este sentido, resulta paradigmático el caso de los partisanos comunistas en Yugoslavia durante la Segunda Guerra Mundial, aunque también el de las guerrillas comunistas china y norvietnamita.

${ }^{30}$ Un buen ejemplo de ello es la tesis doctoral inédita de David ALEGRE LORENZ, Experiencia de guerra y colaboracionismo político-militar: Bélgica, Francia y España bajo el Nuevo Orden (1941-1945), Universitat Autònoma de Barcelona, 2017, que sitúa estas cuestiones como ejes vectores de esta investigación comparada y transnacional en el marco de la Segunda Guerra Mundial.

${ }^{31}$ Véase Joseph G. FRITZ, Frontsoldaten..., op. cit.
} 
dictado de las estructuras o de la fatalidad, sino que son agencias con capacidad para condicionar el entorno a través de sus decisiones y sus actos individuales o colectivos, algo que han puesto de manifiesto los estudios de la guerra en repetidas ocasiones ${ }^{32}$. Por eso mismo, creo necesario señalar que la vida cotidiana es una vía más a explorar de cara a desvelar la naturaleza de los conflictos, las dinámicas por las que se rigen y la forma en que operan los estados modernos en su sostenimiento y prosecución ${ }^{33}$.

Uno de los principales aspectos del día a día de la guerra ha sido la gestión del hambre, elevada a la categoría de estrategia en todos los enfrentamientos armados desde el principio de los tiempos. No es casual que los conflictos queden asociados a la escasez, las hambrunas o, utilizando un concepto contemporáneo, las "crisis humanitarias". Esto viene propiciado en buena medida por las destrucciones, por la ausencia o muerte de los agricultores y ganaderos que sostienen el tejido productivo y comercial de una región o un país, por el bloqueo de las vías de abastecimiento y los sitios contra poblaciones o por la exacción de los recursos alimentarios a manos de una potencia invasora. No obstante, la guerra total planteó un reto sin igual a unos estados obligados a gestionar la planificación, producción, envío y distribución de unas cantidades de recursos sin precedentes destinadas a sostener a los ejércitos de masas y a las sociedades movilizadas en el frente doméstico, pero también el desarrollo e innovación en el campo de la industria alimentaria ${ }^{34}$.

Hay que tener en cuenta la aparición del «primer sistema alimentario global» a finales del siglo XIX, que no sólo quedó disuelto a causa del impacto de la Gran Guerra, sino que a corto y largo plazo propició una crisis socio-económica y político-

\footnotetext{
${ }^{32}$ Como caso de estudio centrado en la vida cotidiana durante la guerra creemos que es paradigmático el estudio de Ivana MAČEK, Sarajevo Under Siege: Anthropology in Wartime, Filadelfia, University of Pennsylvania Press, 2011. La autora nos sumerge en el Sarajevo sitiado por las tropas serbo-bosnias entre 1992 y 1995, analizando la actitud, las redes de sociabilidad, las percepciones y las estrategias de supervivencia de los civiles. En esta misma línea podemos destacar el estudio de Michael JONES, El sitio de Leningrado, 1941-1944, Barcelona, Crítica, 2008.

${ }^{33}$ Una visión coral muy sugerente sobre la vida cotidiana en el frente doméstico alemán durante la Gran Guerra en Jens FLEMMING, Klaus SAUL y Peter-Christian WITT (eds.), Lebenswelten im Ausnahmezustand. Die Deutschen, der Alltag ud der Krieg, 1914-1918, Frankfurt, Peter Lang, 2011.

${ }^{34}$ Véase por ejemplo el trabajo de Ulrike THOMS, "The Innovative Power of War: The Army, Food Sciences and the Food Industry in Germany in the Twentieth Century", en Ina ZWEINIGERBARGIELOWSKA, Rachel DUFFETT y Alain DROUARD (eds.), Food and War in Twentieth Century Europe, Farnham, Ashgate, 2011, pp. 247-262. Esta dimensión modernizadora de la guerra no debe ser vista como algo necesariamente positivo si tenemos en cuenta que lo que ha promovido es el crecimiento y concentración de una industria alimentaria basada en los alimentos procesados, además de la reducción de costes y el aumento de la producción a cualquier precio.
} 
cultural de consecuencias incalculables ${ }^{35}$. Entre otras muchas cosas, el conflicto del 14 evidenció la dependencia de los estados y sociedades europeas frente a las redes comerciales forjadas por ese incipiente mercado mundial del siglo XIX, sobre todo en el caso de Alemania. Esta realidad vino aparejada en muchos países a una obsesión por la demografía y la necesidad de aumentar la natalidad como síntoma de vitalidad y fuente de la que nutrir ejércitos mayores ${ }^{36}$. El deseo de los estados por sobreponerse frente a la dependencia exterior no hizo sino alimentar proyecciones imperiales, visiones autárquicas y guerras de conquista, lo cual no dejaba de ser una consecuencia directa de las crisis del capitalismo. En buena medida, esto explica que la violencia y la lucha armada fueran concebidos como instrumentos políticos y resultaran aceptables para importantes sectores de las sociedades europeas. Al mismo tiempo, nos ayuda a entender el grado de «saqueo sin precedentes, destrucción y redistribución de alimentos bajo los dictados de la expansión y la ocupación totalitaria» durante la Segunda Guerra Mundial ${ }^{37}$.

En este sentido, la relación entre guerra y comida, pero también la forma en que se gestiona el reparto de alimentos o el éxito a la hora de privar al enemigo del

\footnotetext{
${ }^{35}$ Precisamente, interpretaciones como la de Avner OFFER, The First World War: An Agrarian Interpretation, Oxford, Oxford UP, 1991 defienden que la derrota alemana tuvo que ver con el desarrollo de la producción alimentaria y los patrones de consumo desde finales del siglo XIX, pero en buena medida también con la aparición de esa red mundial para el comercio de alimentos que tendría a Canadá, Australia y Estados Unidos como principales potencias exportadoras.

${ }^{36}$ Para el caso británico resulta extremadamente interesante Richard A. SOLOWAY, Demography and Degeneration: Eugenics and the Declining Birthrate in Twentieth-Century Britain, Chapel Hill, The University of North Carolina Press, 1995 [1990], un clásico fundamental en el que la guerra, como no podría ser de otro modo, tiene un peso clave para entender los diagnósticos y miedos de la época y el modo en que hicieron evolucionar a la biopolítica. Muy interesante para el caso del fascismo italiano, en una línea similar, Carl IPSEN, Dictating Demography: The Problem of Population in Fascist Italy, Cambridge, Cambridge UP, 1996. Más recientemente, para el caso francés, la interesante obra de Margaret COOK ANDERSEN, Regeneration through Empire: French Pronatalists and Colonial Settlement in the Third Republic, Lincoln y Londres, University of Nebraska Press, 2015, que conecta algunas obsesiones de la época (como la sensación de crisis o la superación del conflicto de clases) con la expansión y dominio colonial en el periodo a caballo entre el siglo XIX y XX. Una visión global de estos mismos problemas, siempre muy en conexión con la evolución y los cambios en el modo de hacer la guerra, para el caso Alemania desde el último tercio del siglo XIX hasta la actualidad en Thomas ETZEMÜLLER, Ein ewigwährender Untergang. Der apokalyptische Bevölkerungsdiskurs im 20. Jahrhundert, Bielefeld, transcript, 2007.

${ }^{37}$ Frank TRENTMANN y Flemming JUST, "Introduction", en Idem (ed.): Food and Conflict in Europe in the Age of the Two World Wars, Basingstoke, Macmillan, 2006, p. 1. En este sentido, véase el estudio colectivo coordinado por Christoph DIECKMANN y Babette QUINKERT (eds.), Kriegsführung und Hunger 1939-1945. Zum Verhältnis von militärischen, wirtschaftlichen und politischen Interessen, Gotinga, Wallstein, 2015, donde se da cuenta de los múltiples intereses que confluyeron en la gestión de los recursos alimenticios dentro del Tercer Reich durante la Segunda Guerra Mundial.
} 
sustento, constituyen vectores definitorios de la vida cotidiana durante los conflictos bélicos. Por supuesto, condicionan las actitudes de la población y los combatientes y, por tanto, la naturaleza y el resultado mismo de los enfrentamiento bélicos ${ }^{38}$. Pero no sólo eso: este vínculo entre guerra y gestión del hambre revelaría también las relaciones de poder, los equilibrios, los privilegios y las jerarquías que regirían las sociedades enfrentadas, así como la naturaleza de sus sistemas políticos, descubriendo realidades muy diversas y complejas a todos los niveles en función de si ponemos el foco en diferentes espacios locales o regionales, en el ámbito urbano o en el rural ${ }^{39}$.

En este punto también es fundamental conocer mejor episodios como la vida de los civiles bajo las bombas, la forma en que son encarados por el estado, las iniciativas y respuestas vecinales destinadas a enfrentarlos, los vínculos comunitarios forjados en estas situaciones. También, no lo olvidemos, la investigación del papel jugado por las relaciones familiares extensas y su funcionamiento, las evacuaciones de niños y niñas y el modo en que afectarían a las familias nucleares, la forma de vivir la muerte en el frente doméstico $y$, también, el modo en que afectaría todo esto a los combatientes lejos de sus hogares. Otras cuestiones de sumo interés son las formas de ocio de las diversas clases sociales o el estudio del lujo en tiempos de guerra, así como el conocimiento que se tendría de todo ello a nivel social y qué reacciones suscitaría.

Finalmente, puede enseñarnos mucho conocer las políticas implementadas por el estado y las comunidades locales para responder a altos grados de devastación

\footnotetext{
${ }^{38}$ La deficiente organización del sistema de abastecimiento del Ostheer durante el inicio de la invasión de la Unión Soviética en 1941, además de la concepción del ataque como guerra de conquista y exterminio, hicieron que el ataque alemán cobrara una naturaleza y una dimensión mucho más radical y sangrienta sobre el terreno. Véase Jeffrey RUTHERFORD, Combat and Genocide on the Eastern Front, 1941-1944, Cambridge, Cambridge UP, 2014, pp. 57-114 (existe edición en castellano bajo el título La guerra de la infantería alemana, Madrid, La Esfera de los Libros, 2017).

${ }^{39}$ Encontramos una buena cata de profundidad e inspiración para futuros estudios de caso en la obra colectiva de Ina ZWEINIGER-BARGIELOWSKA, Rachel DUFFETT y Alain DROUARD (eds.), Food and War..., op. cit., que es seguramente el trabajo más ambicioso por la diversidad de escenarios que engloba. El estudio de Miguel Ángel DEL ARCO BLANCO, Hambre de siglos. Mundo rural y apoyos sociales del primer franquismo en Andalucía Oriental (1936-1951), Granada, Comares, 2007 explica cómo el franquismo construyó sus apoyos sociales y controló a sus opositores reales o potenciales en la guerra y la posguerra mediante la gestión del hambre y la puesta en marcha de la autarquía. Para el caso de Rusia durante la Gran Guerra véase Lars LIH, Bread and Authority in Russia, 1914-21, Berkeley-Los Angeles-Oxford, University of California Press, 1990 y en lo referente a la Unión Soviética durante la Segunda Guerra Mundial véase William MOSKOFF, The Bread of Affliction: The Food Supply in the USSR During World War II, Cambridge, Cambridge UP, 2002.
} 
debidos a los bombardeos, los cuerpos de bomberos y las unidades auxiliares de vecinos y vecinas, las labores de desescombro, el tratamiento de proyectiles no detonados, la forma en que se asignarían nuevos hogares y recursos materiales a los damnificados, el funcionamiento de redes clientelares en estos casos, los tratos de favor, etc. De hecho, en el afán por analizar el hecho violento o bélico acabamos por ver que la cooperación y la solidaridad son vectores esenciales de dichas experiencias, tanto al nivel de las víctimas como al nivel de los verdugos, condiciones ambas que a menudo se solapan en la misma persona. Todo esto nos lleva a la cuestión de los refugiados en la guerra total, un tema que por lo general pondría a prueba la solidaridad intracomunitaria y la idea de comunidad nacional hasta el punto de generar conflictos graves entre los acogidos y los que acogen. Así pues, merece la pena intentar acercarse al modo en que se reorganizaron los vecinos, a la convivencia, a las percepciones cruzadas o a la violencia cotidiana y los abusos de todo tipo ${ }^{40}$.

\section{La historia transnacional y comparada como marco para la comprensión de la violencia de masas y la guerra}

Y si los individuos han reclamado su derecho a tomar parte en los asuntos públicos durante la contemporaneidad, los estados no han sido menos exigentes a la hora de demandar a sus ciudadanos sacrificios en nombre del bien común. Precisamente, esto último nos ayuda a entender el alcance que pueden llegar a cobrar los conflictos y la violencia de masas en la contemporaneidad. Sin ir más lejos, dentro de la relación entre el estado y las sociedades, el paso por el servicio militar obligatorio, la marcha a la guerra o la colaboración en procesos de violencia de masas se convirtieron en formas extremas de participación política; maneras de mostrar el propio compromiso y valor, así como de reforzar la virilidad; en definitiva, méritos de cara a la consecución de la respetabilidad y la integración del individuo en la comunidad nacional ${ }^{41}$. Hay que partir de la idea de que en el pasado la guerra o la

\footnotetext{
${ }^{40}$ Sobre los refugiados franceses en la Segunda Guerra Mundial véase Nicole DOMBROWSKI RISER, France Under Fire. German Invasion, Civilian Flight, and Family Survival during World War II, Nueva York, Cambridge University Press, 2012.

${ }^{41}$ Sobre la relación directa que existe entre la idea y la práctica de la participación política y la emergencia de lo que él denomina sociedades extremadamente violentas véase Christian GERLACH, "Extremely violent societies: an alternative to the concept of genocide", 8:4 (2006), p. 461.
} 
violencia no tuvieron por qué estar asociadas a las connotaciones negativas que tienen hoy en día de forma mayoritaria en nuestras sociedades occidentales.

Todo esto ha hecho posible entre otras cosas la emergencia de nuevas maneras de rebuscar en el pasado y reflexionar sobre él, como la historia comparada, que se ha lanzado a la búsqueda de marcos interpretativos y contextos más omnicomprensivos. Lo mismo puede decirse de la historia transnacional, en línea con los propósitos anteriormente señalados, que ha señalado la necesidad de dar con las múltiples interconexiones que operan en todo fenómeno histórico que se precie. En pocos acontecimientos es tan posible y se hace tan manifiesta e ineludible la necesidad de los análisis comparativos y transnacionales como en las prácticas violentas y las guerras, sobre todo por su terrible capacidad para confrontar y poner en contacto diferentes realidades ${ }^{42}$. $Y$ esto es extensible en última instancia a todos los asuntos militares, afectando a todos los grupos armados y fuerzas de seguridad en su conjunto, muy lejos del carácter retrógrado y reaccionario que muchas veces se les presupone, más peyorativo e ideológico que basado en un conocimiento bien contextualizado.

A pesar de un fuerte componente identitario de tipo corporativo, el mundo militar reúne en su seno perfiles y grupos humanos de lo más variado, más aún en el tiempo de la sociedad de masas y la guerra total. Estas dos realidades hicieron del militar profesional (o del policía) un individuo muy conectado a su tiempo y posibilitaron transferencias culturales constantes entre espacios y personas de muy diferentes

\footnotetext{
${ }^{42}$ En este punto hay que destacar el trabajo de Ángel ALCALDE, War Veterans and Fascism in Interwar Europe, Cambridge, CUP, 2017, que profundiza en las redes internacionales, así como los discursos y los constructos simbólicos compartidos sobre los cuales se sustentó y reforzó la relación entre algunos sectores de excombatientes de la Gran Guerra y el fascismo en toda Europa. También el espionaje y las sociedades secretas asociadas al mundo militar son marcos propicios para explorar las conexiones transnacionales, como se destaca en la obra colectiva de Gundula GAHLEN, Daniel M. SEGESSER y Carmen WINKEL (eds.), Geheime Netzwerke im Militär, 1700-1945, Paderborn, Ferdinand Schöningh, 2016. Lo mismo puede decirse del terrorismo y de la guerra de guerrillas, que han puesto a prueba los resortes de los estados y su monopolio de la violencia a lo largo de la segunda mitad del siglo XX, como destaca Didier BIGO, "Guerres, conflits, transnational et territoire (Partie 1)", Cultures \& Conflits, 21-22 (1996), pp. 397-418. La solidaridad y la cooperación entre potencias en marcos de dominación, explotación y guerra colonial en el marco de la descolonización también constituye un buen escenario donde captar la importancia de la dimensión transnacional de la historia de los conflictos, como demuestra Samuel Fury DALY, "De trabajadores a soldados: trabajo forzado y conscripción en la Guinea Española y la Nigeria oriental, 1930-1970", Millars, 2017, en prensas. Sobre la importancia de los manuales desarrollados por el ejército francés y estadounidense en los discursos y praxis antisubversivas aplicadas por el ejército argentino en los años 60 y 70 de forma casi contemporánea véase Esteban PONTORIERO, "«Preparativos de guerra»: Ejército, doctrina antisubversiva y planes represivos en los orígenes del terror de Estado, 1973-1976", Revista Universitaria de Historia Militar, 5:10 (2016), pp. 319-339.
} 
latitudes ${ }^{43}$. Lejos de constituir un halago hablamos de un hecho evidente que debe ser un punto de partida inexcusable en nuestros análisis sobre lo militar, lo bélico y lo violento, porque esto nos aportará claves para comprender un tema tan esencial como controvertido: las diferentes formas en que los militares y las fuerzas de seguridad han intervenido (e intervienen) en la vida pública y política a lo largo de la contemporaneidad, pero también las particularidades (con sus similitudes y diferencias) de las diversas culturas militares y su puesta en práctica durante las guerras.

Desde luego, vamos hacia un modo mucho más refinado y exigente de hacer historia y de entenderla, un modelo que aboga fundamentalmente por la necesaria complejización de nuestras visiones del pasado. Éste combina múltiples dimensiones o niveles de la realidad, integra las voces de actores diversos y hace hincapié al mismo tiempo en cuestiones como el género, lo cotidiano, lo local y regional, lo económico, lo social, lo político o lo cultural. Además, se trata de una nueva propuesta de análisis que trata de huir de los enfoques teleológicos recuperando la contingencia histórica, pero que entiende lo violento y lo bélico como fenómenos enmarcados en procesos acumulativos y, también, en proyecciones de futuro evocadas por los propios contemporáneos a los hechos.

En este sentido parecen apuntar los últimos trabajos sobre el genocidio armenio, que van mucho más allá de las primeras explicaciones sobre la paranoia quintacolumnista, la disolución del imperio otomano, la posición fronteriza de los armenios y las conspiraciones palaciegas de los Jóvenes Turcos. Gracias a los estudios a ras de suelo han aparecido en escena las diferencias territoriales con sus equilibrios intercomunitarios y el papel de las autoridades locales, así como la implicación de múltiples agencias estatales, todo lo cual no excluye ninguna de las explicaciones clásicas anteriormente mentadas. También se empieza a descubrir quiénes se beneficiaron de las políticas de la violencia implementadas al este de

\footnotetext{
${ }^{43}$ Muy bien visto para el caso de España por Geoffrey JENSEN, Las culturas militares españolas. Modernistas, tradicionalistas y liberales, Madrid, Biblioteca Nueva, 2014, donde el autor analiza los perfiles biográficos de militares españoles prominentes asociados a corrientes culturales y políticas distintas. Para el caso de Francia y el impacto que tuvieron en España los debates sobre la moralidad y la vida cotidiana del ejército francés a finales del siglo XIX véase Jordi LUENGO LÓPEZ, "Homoerótica entre líneas...", op. cit. Para el caso del ejército italiano, el alto nivel cultural y las múltiples conexiones de su cuerpo de oficiales en el mundo internacional véase Jacopo LORENZINI, "Managing the Army, governing the State: the Italian military élite in national politics 1882-1915", Revista Universitaria de Historia Militar, 6:11 (2017), en prensas.
} 
Anatolia, que afectaron a muchos más colectivos aparte de los armenios; qué motivaciones movían a los perpetradores; $y$, por último, qué efectos aglutinadores tuvo a largo plazo la destrucción de este grupo o el ataque contra otras comunidades, decisivos en la forja del moderno estado turco y la sociedad bajo su control ${ }^{44}$. Evidentemente, lo humano no responde a programas prefijados, de manera que siempre debemos tener en mente que a medio-largo plazo los actores históricos desconocen el resultado último de sus discursos, decisiones y prácticas, y que, como prueba la riqueza de las experiencias políticas, sociales, violentas y bélicas del periodo de entreguerras, no tenía por qué ser unívoco.

Desde luego, la violencia de masas suele ir asociada a las guerras desde el principio de los tiempos, aunque no siempre sea necesario un contexto bélico para su puesta en marcha. En cualquier caso, esta relación se ha visto intensificada y diversificada en la modernidad, de ahí que hable constantemente de ambos fenómenos a la par. Sencillamente ha acabado resultando cada vez más difícil distinguir las formas convencionales de hacer la guerra de la violencia pura y simple, es decir, aquellas operaciones o actos aislados que escapan de la legislación internacional que regula los conflictos ${ }^{45}$. Al fin y al cabo, las políticas de la violencia adoptan una u otra forma en función del entorno en que se aplican, las ideas que tienen detrás, los medios con que se cuenta y se llevan a cabo y, no menos importante, el carácter o la naturaleza de los actores que las inspiran y ponen en marcha. Por eso tiene poco sentido aislar el Holocausto del resto de acontecimientos de la contemporaneidad o convertirlo en un punto de referencia en base al cual se mesuran el resto de experiencias violentas de su tiempo, ya que han tenido lugar multitud de episodios de violencia masiva, la mayor parte de ellos fuera de Europa, que sólo son comparables hasta cierto punto con el exterminio de los judíos. En cualquier caso, hay que reconocer la importancia decisiva de los llamados estudios sobre el Holocausto y el genocidio, que más allá de sus problemas conceptuales y sus límites

\footnotetext{
${ }^{44}$ Christian GERLACH, “Extremely violent societies...”, op. cit., pp. 457-459 y 469.

${ }^{45}$ Véase por ejemplo Omer BARTOV, A. GROSSMANN y M. NOLAN (eds.), Crimes of War: Guilt and Denial in the Twentieth Century, Nueva York, The New Press, 2003.
} 
han sido claves a la hora de conectar las violencias de masas con los estudios de la guerra y, por extensión, con sus dimensiones sociales y culturales ${ }^{46}$.

Los diferentes procesos violentos de los siglos XX y XXI están marcados por sus propios tempos $\mathrm{y}$, también, por causas endógenas y exógenas exclusivas que se combinan entre sí de formas diversas, a pesar de las similitudes entre casos diferentes ${ }^{47}$. A menudo, los propios conflictos armados se han convertido y se convierten en marcos propiciatorios para la construcción de nuevos estados, paraestados o experimentos políticos de diverso signo que cobran forma al calor de las propias dinámicas de guerra y de las violencias asociadas a éstas. No obstante, también han contribuido a su disolución y final o se ha recurrido a ellas como forma desesperada de intentar reforzar estados débiles o en fase de disolución ${ }^{48}$. Una comprensión mucho más amplia y descentralizada de la guerra y la violencia pasa por entender que, por ejemplo, los desplazamientos forzosos de poblaciones nos ayudan a analizar los intentos del estado por reforzar su autoridad variando los equilibrios étnicos y los potenciales apoyos en regiones real o potencialmente refractarias. Ya antes había ocurrido algo muy similar, aunque mucho más radical y definitivo, con la huida y expulsión de casi quince millones de alemanes (o considerados como tal por cuestiones político-culturales y socio-económicas) en una amplia faja territorial que iría

\footnotetext{
${ }^{46}$ A este respecto la revista Holocaust and Genocide Studies es una referencia insoslayable en el tratamiento de estas problemáticas y un lugar de confluencia para expertos de las más diversas disciplinas y procedencias. Sobre los estudios del genocidio véase la obra de Antonio Míguez, que es seguramente quien más ha hecho por acercar a la historiografía española los polémicos y vivos debates en torno a este concepto, adoptándolo además al estudio de la violencia sublevada primero y represión franquista después. Véase Antonio MíGUEZ MACHO, "1961. Los términos del debate sobre la naturaleza de la violencia franquista", en Idem (ed.), Ni verdugos ni víctimas. Actitudes sociales ante la violencia, del franquismo a la dictadura argentina, Granada, Comares, 2016. Autores como Mark Levene consideran que el genocidio no sólo no es un fenómeno histórico extraño o puntual, sino que es inherente al proceso de forja de un sistema mundial de estados-nación y, por tanto, va asociado a la compleja disolución de los grandes imperios multinacionales. Véase Mark LEVENE, The Crisis of Genocide. Volume I: Devastation. The European Rimlands 1912-1938 y Volume II: Annihilation. The European Rimlands 1939-1953, Oxford, Oxford UP, 2014. Sin embargo, a pesar de la contundencia de su trabajo el autor olvida que sociedades como la francesa o la neerlandesa, pertenecientes al triángulo de naciones-estado "consolidadas", tomaron parte activa en el Holocausto.

${ }^{47}$ La importancia de las conexiones transnacionales e internacionales en la puesta en marcha de escenarios de enfrentamiento fratricida es destacada desde la polemología por Kristian Skrede GLEDITSCH, "Transnational Dimensions of Civil War", Journal of Peace Research, 44:3 (2007), pp. 293309.

${ }^{48} \mathrm{El}$ control de las políticas retributivas dirigidas contra los colaboracionistas por parte de los estados reconstituidos en los compases finales de la Segunda Guerra Mundial fue un instrumento clave en la construcción de su poder, en su legitimación y en la refundación del orden y los equilibrios sociales. Véase István DEÁK, Jan T. GROSS y Tony JUDT (eds.), The Politics of Retribution in Europe: World War II and Its Aftermath, Princeton, Princeton UP, 2000.
} 
desde el mar Báltico hasta el mar Negro, con multitud de causas, actores y tempos ${ }^{49}$. En definitiva, los propios enfrentamientos bélicos suelen cobrar vida, forzando la toma de decisiones tanto en las altas esferas como a ras de suelo, con sinergias mutuas y con acciones que no habían sido previstas en un primer momento.

\section{Estado y sociedad: la importancia de los enfoques locales y regionales y el necesario diálogo entre las visiones desde arriba y desde abajo}

Efectivamente, en los conflictos modernos siguen teniendo un lugar fundamental los espacios locales-regionales y las autoridades carismáticas o señores de la guerra radicados en ellos, sobre todo en situaciones de "vacío de poder" ${ }^{50}$. No obstante, la feudalización o fragmentación de la autoridad siempre convive de iure y/o de facto con formas de estado o agencias superiores que conservan grados de poder e influencia diversos. Mark Mazower lo dejaba muy claro cuando decía que «es obvio que la lógica del interés de estado es insuficiente para explicar la violencia, [algo que también vale para el caso de la guerra]. ¿Debemos buscar factores más individualistas y subjetivos? No necesariamente: entre el nivel del estado y el del perpetrador individual está el de los poderosos locales y regionales» ${ }^{51}$. Sea como fuere, y cabe hacer hincapié en ello, este tipo de fenómenos también pueden tener lugar en el marco de la construcción de nuevos estados o en la expansión de otros preexistentes, que es un escenario que también debe ser considerado.

\footnotetext{
${ }^{49}$ Sobre las expulsiones de poblaciones en la Europa de la segunda posguerra mundial véase la obra colectiva de Jessica REINISCH y Elizabeth WHITE (eds.), The Disentanglement of Populations: Migration, Expulsion and Displacement in Post-War Europe, 1944-49, Basingstoke, Palgrave, 2011.

50 Sobre la importancia de la violencia, la guerra, el ejército y los poderes locales o regionales en la construcción del estado argentino a lo largo del siglo XIX véase Flavia MACíAS, Armas y política en la Argentina. Tucumán, siglo XIX, Madrid, CSIC, 2014. Las particularidades de la movilización en la Alemania septentrional durante los inicios de la Gran Guerra en Cornelia RAUH, Arnd REITEMEIER y Dirk SCHUMANN (eds.), Kriegsbeginn in Norddeutschland. Zur Herausbildung einer «Kriegskultur» 1914/15 in transnationaler Perspektive, Wilhelmshaven, Wallstein, 2015. Para el caso de los estado postsoviéticos véase Jesse DRISCOLL, Warlords and Coalition Politics in Post-Soviet States, Nueva York, Cambridge UP, 2015. Más allá de Europa tenemos el caso sudafricano, abordado por Sarah M. MATHIS, "Warlords to Freedom Fighters: Political Violence and State Formation in Umbumbulu, South Africa", African Affairs, 112:448 (2013), pp. 421-439.

${ }^{51}$ Mark MAZOWER, "Violencia y estado en el siglo XX”, Historia Social, 51 (2005) p. 147.
} 
En este sentido, los equilibrios comunitarios sobre el terreno, y hablamos a nivel micro, son especialmente importantes a la hora de comprender la complejidad inherente a los procesos de control político-social, a la movilización socio-económica y a las políticas de la violencia que se ponen en marcha en el marco de cualquier guerra moderna $^{52}$. Las investigaciones que han partido de este escenario como objeto de estudio han dado resultados extraordinarios, por eso mismo, seguir ahondando en la naturaleza y funcionamiento de la guerra total pasa por realizar piezas de batalla, por analizar lo que ocurre en espacios localizados de la retaguardia, por comprender que en un mismo conflicto pueden y suelen solaparse luchas armadas y procesos violentos de diversa naturaleza, etc ${ }^{53}$. En definitiva, volver la mirada hacia las particularidades de los escenarios locales, conectando esto con lo que ocurre a un nivel más amplio y global, resulta fundamental para la comprensión de las políticas de la violencia o las guerras totales, y la mayor parte de los teatros de la Segunda Guerra Mundial constituyen un caso paradigmático en este sentido.

No es casualidad que hayan discurrido por aquí algunos de los estudios más influyentes de los últimos años en torno a la violencia de masas en los países y territorios ocupados por el Tercer Reich. Estos se han mostrado muy preocupados por ofrecernos una adecuada contextualización coyuntural y estructural, un buen conocimiento de los perpetradores y sus repertorios y bases documentales amplias que revelan la multiplicidad de autores e intereses que confluyen en este tipo de procesos $^{54}$. Ese mismo enfoque se ha empezado a aplicar ya con notables resultados para el caso italiano entre 1935 y 1945, si bien seguimos pendientes de que se haga para el caso de la España sublevada durante la guerra civil, así como también en muchos otros escenarios bélicos ${ }^{55}$. Por eso mismo, hay que tener en cuenta que los

\footnotetext{
52 Resulta muy interesante el trabajo de Assumpta CASTILLO CAÑIZ, "EI forastero", Revista Universitaria de Historia Militar, 3:6 (2015), pp. 12-27, sobre la importancia de los vínculos intracomunitarios e interregionales en las movilizaciones bélicas y la puesta en marcha de violencias de diverso signo.

${ }^{53}$ Para el caso de España sigo considerando ineludible Javier RODRIGO, "Retaguardia: un espacio de transformación", Ayer, 76 (2009), pp. 13-36. Sobre la concatenación de procesos y conflictos diversos véase Pavel K. BAEV, "Defining Civil War by Examining Post-Soviet Conflicts", Terrorism and Political Violence, 19:2 (2007), pp. 247-268.

${ }^{54}$ Karel C. BERKHOFF, Harvest of Despair: Life and Death in Ukraine Under Nazi Rule, Cambridge (MA) y Londres, Belknap Press of Harvard UP, 2004.

${ }^{55}$ Para el caso italiano véase Amedeo OSTI GUERAZZI, The Italian Army in Slovenia: Strategies of Antipartisan Repression, 1941-1943, Basingstoke, Palgrave, 2013. Para el caso croata véase el estudio
} 
estados no siempre juegan el papel omnipresente que se les presupone en los procesos de violencia y en las particularidades de las movilizaciones bélicas. Sin embargo, sí que contribuyen en muchos casos a crear el escenario adecuado y a poner en marcha las relaciones necesarias para que ocurran ciertos conflictos, lo cual no es poca cosa. Buena muestra de ello es la expansión colonial de los Estados Unidos y Australia y la racionalización de los territorios situados al oeste de las colonias originales. En estos casos, autoridades metropolitanas muy distantes se veían obligadas a sancionar hechos consumados y fronteras empujadas cada vez más lejos, todo ello acompañado por la matanza y expulsión forzosa de pueblos indígenas que, eso sí, estaba amparada por discursos supremacistas y códigos culturales bien asentados $^{56}$.

Por tanto, basta con subrayar que las relaciones entre un estado -sea este "campamental" o bien consolidado- y su ciudadanía no son ni mucho menos unívocas, menos en el escenario de un conflicto armado o de violencia de masas. Más bien al contrario, éstas se caracterizan por múltiples matices que deben ser tenidos en cuenta y desentrañados para entender la naturaleza de estos fenómenos colectivos. Finalmente, lo que pretendo señalar es que no sólo (y desde luego no siempre) los estados tienen la omnipotencia y capacidad performativa que muchas veces se les presupone casi como un lugar común. En realidad, las propias sociedades o, sobre todo, sectores concretos de éstas tienen una gran capacidad para moldear a las instituciones e imponer o reconducir ciertas políticas por diversos medios. Esto, claro está, es aplicable a las dos formas de política más extremas: la violencia de masas y la guerra.

No por nada, el estallido de un "nuevo" tipo de guerra en 1914 dio lugar al reforzamiento del aparato estatal y la burocracia, generando una gigantesca maquinaria represiva y de control de los ciudadanos muy inspirada en los códigos

\footnotetext{
imprescindible de Alexander KORB, Im Schatten des Weltkrieges. Massengewalt der Ustaša gegen Serben, Juden und Roma in Kroatien 1941-1945, Hamburgo, Hamburger Edition, 2013.

${ }^{56}$ Un estado de la cuestión para el caso australiano, donde se debate sobre la pertinencia del concepto genocidio para analizar las políticas expansionistas dentro de las colonias de dicho continente, en Thomas James ROGERS, "Genocide and Frontier Violence in Australia", Journal of Genocide Research, 18:1 (2016), pp. 83-100. Una interesante y provocadora perspectiva comparada sobre el caso estadounidense la encontramos en Carroll P. KAKEL, The American West and the Nazi East: $A$ Comparative and Interpretative Perspective, Basingstoke, MacMillan, 2011. Muy interesante la visión de largo alcance de Matthew J. FLYNN, Settle and Conquer: Militarism on the American Frontier, 16071890, Jefferson, McFarland, 2016.
} 
militares y los automatismos de los ejércitos modernos. El propio conflicto sirvió como pretexto para ello. Una maquinaria que, además, según ciertas visiones parece que tuvo la facultad de imponer y llevar a cabo al milímetro planes de guerra y de exterminio prefijados, cumpliendo sus objetivos de forma diligente y total, casi diríamos que de forma pura y obediente. No obstante, estas hipótesis resultan de una concepción excesivamente rígida de las jerarquías y los rudimentos que operarían en las estructuras estatales o los ejércitos. En este sentido, podría decirse que no tienen un fundamento en la realidad $o$, al menos, no funcionan de forma tan exacta como a veces se ha querido ver. El éxito en la guerra moderna pasa muy a menudo por la interpretación que las unidades militares hacen del escenario o situación que enfrentan, muy lejos por lo general de los centros de mando supremos.

En este sentido, las decisiones adoptadas por los comandantes de las divisiones que operan sobre el terreno y ejecutan las grandes directrices emanadas de los cuarteles generales resultan decisivas para el curso de la guerra. Así ocurrió en un caso paradigmático como es el de la contraofensiva soviética en el invierno de 194142, cuando contraviniendo directamente las órdenes de Hitler el comandante del Panzergruppe 2, Heinz Guderian, encargado de cerrar el cerco sobre la capital soviética desde el sur, decidió emprender una serie de retiradas ante la desesperada situación de sus tropas en la segunda mitad de diciembre. Esta decisión, que seguramente salvó a las fuerzas alemanas implicadas de ser completamente cercadas y destruidas e hizo posible resistir ante la presión soviética, acabó con Guderian enfrentado a sus superiores y siendo enviado a la reserva, destino que compartió con otros cuarenta oficiales que adoptaron medidas similares. La cosa no cambia si descendemos hasta el nivel de los oficiales intermedios al mando de los grupos de combate más reducidos y las operaciones sobre el terreno, que necesariamente deben ser autónomos y capaces de responder ante las dificultades e imprevistos que pudieran presentarse. Este enfoque de la guerra fue codificado por primera vez por el ejército prusiano en pleno siglo $\mathrm{XIX}$, convirtiéndose en uno de los rasgos más distintivos de su cultura militar, y da buena cuenta de la importancia de los escenarios 
localizados y los individuos concretos cuando hablamos de la guerra o, por extensión, de la violencia ${ }^{57}$.

Existen unas directivas y unos propósitos, está claro, pero quienes las reciben y deben implementarlas tienen su propia lectura de la situación, sus propios intereses y su visión de cuál es el mejor modo de ejecutar los planes. Por tanto, dentro de las estructuras estatales y los ejércitos ha existido y existe necesariamente margen de maniobra, como también lo hay en las sociedades en guerra, a pesar de que el abanico de posibilidades para actuar se vea restringido de forma más que notable por las circunstancias derivadas de la naturaleza de cada conflicto. A pesar de todo, las investigaciones gozan de buena salud y marchan por buen camino: en los últimos años se ha cuestionado más que nunca esa supuesta omnipotencia de las burocracias estatales, en realidad forzadas a "negociar" y "contemporizar" con unas sociedades civiles que a niveles regionales y locales constituyen un agente más, y no un mero receptor de políticas ${ }^{58}$.

Aquí cobra pleno sentido aquella frase de Charles Tilly según la cual «La guerra hizo al estado y el estado hizo la guerra», que pone de manifiesto los cambios y transformaciones sufridos por las estructuras estatales en su necesidad de adaptarse a conflictos armados cada vez más exigentes. Pero esto también ocurre a la inversa: los estados también se vieron en la necesidad de promover formas de hacer la guerra cada vez más ambiciosas y efectivas (ergo más destructivas) con el fin de imponerse a sus enemigos. Nada de esto debe llevarnos a suponer que más guerra implique más estado, ya que los enfrentamientos armados y las movilizaciones asociadas a éstos pueden llegar a tensar las costuras de las instituciones estatales (y las sociedades a su cargo) hasta cuestionar su autoridad y provocar su propia destrucción ${ }^{59}$. Disponemos

\footnotetext{
${ }^{57}$ Sobre las particularidades de la cultura militar prusiana y su relación con los cambios acontecidos en la nueva sociedad alemana véase MacGregor KNOX, "The 'Prussian Idea of Freedom' and the Career Open to Talent. Battlefield Initiative and Social Ascent from Prussian Reform to Nazi Revolution, 18071944", en ídem, Common Destiny: Dictatorship, Foreign Policy, and War in Fascist Italy and Nazi Germany, Nueva York, Cambridge University Press, 2000, pp. 186-226.

${ }^{58}$ Esta negociación es fundamental a la hora de favorecer la movilización de los recursos humanos de un país dado, como también lo es contar con los equilibrios locales y regionales y los intereses individuales en el impulso de la violencia de masas. Véase Pierre PURSEIGLE, "La primera guerra mundial y las transformaciones del Estado", Revista Universitaria de Historia Militar, 3:5 (2015), pp. 165186.

${ }^{59}$ Sobre estas cuestiones véase la obra de referencia de Charles TILLY, Coerción, capital y los Estados europeos, 990-1990, Madrid, Alianza, 1992 [1990].
} 
de múltiples ejemplos en la época contemporánea, que van desde la disolución del Segundo Imperio francés a causa de la guerra franco-prusiana hasta la de los imperios ruso, austro-húngaro, otomano o alemán durante la Gran Guerra ${ }^{60}$.

\section{Entre la ruptura y la continuidad: la posguerra como marco de estudio de la guerra total}

No podemos olvidar las políticas de reconstrucción en la posguerra, por lo general un momento de gran efervescencia en cuanto a proyectos e intercambio de experiencias. $Y$ cuando hablo de reconstrucción me refiero a ella en términos puramente físicos (paisajísticos, urbanísticos y arquitectónicos), pero también culturales, políticos e identitarios. Reconstruir al individuo física y psíquicamente; a la comunidad local y nacional fracturada por la violencia y la muerte; pero también la territorialidad del estado, las instituciones y formas de organización a diferentes niveles, todo ello con el fin de alcanzar un mejor control de la ciudadanía o una gestión más efectiva. No menos importante, las posguerras vienen marcadas por la necesidad de poner en marcha los sistemas de protección y promoción de mutilados y mutiladas, viudos y viudas, huérfanos y huérfanas; la recuperación y destrucción de explosivos no detonados y armamento inutilizado; las estrategias para la reactivación económica de zonas especialmente devastadas y la restauración del tejido productivo y las comunicaciones; la recepción y puesta en marcha de las posibles reivindicaciones de los diferentes colectivos organizados, como los excombatientes; la asignación de recursos materiales para la reconstrucción y el racionamiento; la autogestión de los propios vecinos en las tareas reconstructivas; los cambios en la trama urbana y el paisaje, con reordenaciones, saneamientos, repoblaciones forestales y todo tipo de políticas; la aparición de la vivienda social; y así un largo etcétera.

Todas las políticas y problemas mencionados son fundamentales para garantizar una vuelta a la normalidad y un nuevo comienzo acorde con las ilusiones y expectativas colectivas generadas por la guerra, pero también para gestionar y paliar sus tremendos estragos. No obstante, la dislocación de las economías nacionales y los

\footnotetext{
${ }^{60}$ Muy recomendable para el caso austro-húngaro el estudio de Jonathan E. GUMZ, The Resurrection and Collapse of Empire in Habsburg Serbia, 1914-1918, Cambrige, Cambridge UP, 2009.
} 
problemas a la hora de acceder a los recursos necesarios dentro del mercado internacional siempre condicionan decisivamente las reconstrucciones, forzando respuestas adaptativas por parte los estados y las sociedades obligadas a superar esas limitaciones. Tampoco hay que olvidar que detrás de toda política de reconstrucción existen unos intereses político-económicos y unas estrategias de control y poder. Por eso mismo también, allá donde es posible, se dan visiones discordantes y pugnas entre proyectos diferentes. Analizar esto exige atender a cuestiones esenciales como los diversos discursos ideológicos y culturales que amparan las reconstrucciones y las restauraciones del orden social, los mecanismos y prioridades en la asignación de recursos, así como también en la culminación de las obras, o, por supuesto, las empresas adjudicatarias y el grado de participación estatal ${ }^{61}$.

\section{Conclusiones: la necesidad de impulsar los estudios de la guerra}

El objetivo de los historiadores y las historiadoras dedicados al estudio de la guerra debe ser captar y representar la experiencia humana en toda su complejidad, desde diferentes sectores de la sociedad y de la forma más cercana posible a la realidad de los contemporáneos, pero también su postura ante las instituciones militares, la violencia y los acontecimientos bélicos ${ }^{62}$. No menos importante, debemos recuperar y transmitir el sufrimiento, pero también los esfuerzos colectivos, las

\footnotetext{
${ }^{61}$ En general no se ha dedicado mucha atención a estas cuestiones desde la historiografía, salvo en temas memorísticos y culturales. Muy interesante la amplia y variada visión que nos ofrece la obra colectiva de Nicholas MARTIN, Tim HAUGHTON y Pierre PURSEIGLE (eds.), Aftermath: Legacies and Memories of War in Europe, 1918-1945-1989, Surrey, Ashgate, 2014. Muy interesante para el caso japonés C. HEIM, J. DIEFENDORF y Y. ISHIDA (eds.), Rebuiding Urban Japan After 1945, Basingstoke, Macmillan, 2003. Algunos casos de investigación interesantes para el caso alemán en Alon CONFINO, Paul BETTS, y Dirk SCHUMANN, Between Mass Death and Individual Loss: The Place of the Dead in Twentieth-Century Germany, Oxford (NY), Berghahn, 2011 [2008]. Para el caso de la posguerra española del 39 tenemos el trabajo regional coordinado por Carlos FORCADELL y Alberto SABIO (eds.), Paisajes para después de una guerra: el Aragón devastado y la reconstrucción bajo el franquismo, 19361957, Zaragoza, IFC, 2008. También el congreso Posguerras: 75 aniversario de la guerra civil española, celebrado en la Universidad Complutense de Madrid en abril de 2014, abundó en estas cuestiones.

${ }^{62}$ Este espíritu está en consonancia con el modo de entender los estudios de la guerra promovido por otra iniciativa, la Revista Universitaria de Historia Militar, cuyos autores y autoras están realizando aportaciones netas en el campo, a la par que contribuyen a visibilizarlo, a transferir nuevos conceptos y a generar debates dentro del mundo hispanohablante.
} 
respuestas y las formas de organizarse para soportar aquello que en tiempos de paz resulta inconcebible. Al mismo tiempo se trata de dar con lo que hay de común entre una experiencia bélica y posbélica concretas, porque la comprensión de la naturaleza de cualquier guerra y de lo que ha supuesto pasa por analizar también sus secuelas en medio de la posguerra. Al fin y al cabo, para muchos ésta constituye un nuevo combate por la supervivencia o, dentro de la posible inestabilidad, una oportunidad para un nuevo comienzo o para cuestionar el orden surgido de la contienda.

Incluso podemos ir más allá, siguiendo las cicatrices de la guerra total para ver cómo la vivencia de conflictos de esta naturaleza marca a las sociedades afectadas por ellos. También el modo consciente e inconsciente en que se transmite dicha experiencia en el seno de la familia, de la comunidad local y de la sociedad en su conjunto $^{63}$. Y merece la pena recuperar una vez más el acertado concepto de Conxita Mir, quien hablaba de los efectos no contables de la represión para referirse a las consecuencias no perceptibles de la violencia de los sublevados durante la guerra civil y la posguerra españolas, como el miedo, la segregación y el aislamiento a nivel social o la brutalidad y las humillaciones en las relaciones intercomunitarias ${ }^{64}$. Desde luego, esos efectos no contables existen en cualquier fenómeno bélico o violencia de masas que se precien. A día de hoy sigue siendo una cuestión pendiente de muchas historiografías dar con el rostro y la realidad de fenómenos derivados directa o indirectamente de las guerras, como la mendicidad; la prostitución; los suicidios; los trastornos mentales; la orfandad; la violencia intrafamiliar; los cambios en el lenguaje y en las relaciones humanas; la violencia de género; las desapariciones voluntarias o forzosas; la inmigración interna; la estigmatización del o la colaboracionista (en este caso sexuada); las perturbaciones en la vida íntima; los problemas para adaptarse a

\footnotetext{
${ }^{63}$ Esto es lo que se propone Javier RODRIGO, Cruzada, Paz, Memoria. La guerra civil en sus relatos, Granada, Comares, 2013, una sugerente propuesta donde analiza las repercusiones de las diferentes narrativas promovidas desde el poder $y$, también, desde la sociedad civil en torno a la guerra española del 36-39, desde sus comienzos hasta la actualidad. Para una visión amplia y comparada de diferentes casos véase Daniel CHIROT, Gi-Wook SHIN y Daniel SNEIDER (eds.), Confronting Memories of World War II: European and Asian Legacies, Washington, University of Washington Press, 2014. Véase también la interesante obra colectiva de Jörg ECHTERNKAMP y Stefan MARTENS (eds.), Experience and Memory: The Second World War in Europe, Nueva York-Oxford, Berghahn, 2010, que reúne una buena cantidad de estudios dedicados a los mitos y la gestión de la memoria de la Segunda Guerra Mundial.

${ }^{64}$ Véase Conxita MIR (ed.), “La represión bajo el franquismo”, Ayer, 43 (2001), pp. 11-35.
} 
nuevos entornos; el drama de los desaparecidos; el traumático reencuentro de los matrimonios tras años de ausencia o desaparición del marido; y así un largo etcétera ${ }^{65}$. En ocasiones, las artes han tenido más fortuna y acierto a la hora de acercarse a la complejidad inherente a las guerras, así como también a sus consecuencias de largo alcance ${ }^{66}$. Como historiadores e historiadoras, eso debería espolearnos a la hora de plantear nuevas investigaciones donde estos fenómenos y problemáticas tengan más presencia o sean el objeto de estudio central.

\footnotetext{
${ }^{65}$ Véase por ejemplo el interesantes estudio de Paul LERNER, Hysterical Men: War, Psychiatry and the Politics of Trauma, 1890-1930, Ithaca, Cornell UP, 2003. Más centrado en la importancia que tuvo la Gran Guerra para la psiquiatría, así como las interpretaciones que se llevaron a cabo del modus operandi de los combatientes o del conflicto mismo en clave patológica Maria HERMES, Krankheit: Krieg. Psychiatrische Deutungen des Ersten Weltkrieges, Essen, Klartext, 2012. En una línea muy similar Joanna BURKE, "Disciplining the Emotions: Fear, Psychiatry and the Second World War", en Roger COOTER, Mark HARRISON y Steven STURDY (eds.), War, Medicine and Modernity, Stroud, Sutton Publishing, 1998. Para el caso de la posguerra española es muy pertinente Óscar RODRÍGUEZ BARREIRA, El franquismo desde los márgenes. Campesinos, mujeres, delatores, menores..., Lleida, Edicions de la Universitat de Lleida, 2013. En lo que respecta al aumento de la violencia de género en el marco de las posguerras encontramos reflexiones de interés en Rashida MANJOO y Calleigh MCRAITH, "Gender-Based Violence and Justice in Conflict and Post-Conflict Areas", Cornell International Law Journal, 44:11 (2011), pp. 11-31.

${ }^{66}$ Entre ejemplos innumerables de época más reciente podemos destacar por su valor humano las obras de Svetlana Aleksievitch, una referencia de primer orden -al fin y al cabo una fuente, al basarse en testimonios orales- para conocer esos efectos no contables de los conflictos en casos como la Segunda Guerra Mundial, la invasión de Afganistán por el Ejército Rojo o las guerras en el Cáucaso de finales del siglo XX. También resulta muy estremecedor y revelador el documental de Aleksander Sokurov, Dukhovnye golosa [Voces espirituales] (1995) sobre los efectos de la lucha en Afganistán sobre los combatientes soviéticos.
} 